\title{
Associations of Daily Eating Episodes, and Eating Away-from-home with Blood Level of Total Cholesterol
}

\author{
Yunsheng Ma, MD, PhD; ${ }^{1 *}$ Elizabeth R. Bertone-Johnson, $\mathrm{ScD} ;^{2}$ \\ Edward J. Stanek III, PhD ${ }^{2}$ Nancy L. Cohen, PhD, RD; ${ }^{3}$ Ira S. Ockene, MD ${ }^{4}$ \\ ${ }^{1}$ Division of Preventive and Behavioral Medicine, University of Massachusetts Medical School, Worcester, MA \\ ${ }^{2}$ Department of Public Health, University of Massachusetts School of Public Health and Health Sciences, Amherst, MA \\ ${ }^{3}$ Department of Nutrition, University of Massachusetts School of Public Health and Health Sciences, Amherst, MA \\ ${ }^{4}$ Division of Cardiovascular Medicine, University of Massachusetts Medical School, Worcester, MA
}

\begin{abstract}
The objective of this investigation is to describe the associations of number of eating episodes and proportion of meals eaten away from home with total serum cholesterol. Data from 499 participants, recruited from a health maintenance organization in central Massachusetts, aged 20-70, were used for this analysis. Dietary information and total blood cholesterol were obtained at five sampling points (baseline and four consecutive quarters) during the one-year follow-up. A cross-sectional study was conducted. The results from the study do not support the hypothesis that the number of eating episodes per day is associated with total blood cholesterol. However, we noted that the mean concentration of total cholesterol decreased with increasing number of eating episodes among women, although the adjusted mean among three categories of number of eating episodes per day was not statistically significant. On the other hand, the results of our study suggest that increased frequency of meals (breakfast, lunch, or dinner) eaten away from home is positively associated with mean total blood cholesterol concentration. Furthermore, meals eaten away from home, especially breakfast and dinner, were significantly higher in total calories, and percent calories from total and saturated fat, but lower in percent calories from protein and carbohydrate, and grams of fiber, than corresponding meals eaten at home. We conclude that eating out may have adverse influences on blood lipids. Further research is needed to better understand the impact of eating away from home on blood lipids.
\end{abstract}

[N A J Med Sci. 2011;4(4):222-231.]

Key Words: eating patterns, epidemiology, diet, cholesterol

\section{INTRODUCTION}

Small, short-term trials in healthy individuals with normal blood lipids have shown that increased frequency of eating may be associated with improved lipoprotein profiles. ${ }^{1-9}$ Furthermore, there are plausible mechanisms by which increased eating frequency might reduce levels of total and LDL-cholesterol. One controlled trial ${ }^{10}$ suggested that a short-term increase in the frequency of eating, with no change in energy intake, results in an acute reduction in postprandial blood glucose and insulin level. Reduction in insulin level may have direct influences on blood cholesterol through its regulation of hepatic cholesterol synthesis; however, the longer-term influences have not been studied and data from free living populations are limited. One study from a free living population in Norfolk, England ${ }^{11}$ suggested that concentration of total cholesterol was negatively and

Received 8/12/2011; Revised 10/12/2011; Accepted 10/14/2011

*Corresponding Author: Division of Preventive and Behavioral Medicine, University of Massachusetts Medical School, 55 Lake Avenue North, Worcester, MA 01655. (Email : Yunsheng.ma@umassmed.edu) consistently associated with frequency of eating. Results have shown a decrease of approximately $5 \%$ total cholesterol in subjects who eat six or more times a day compared with those who eat once or twice a day. ${ }^{11}$ However, there is no report on the US population.

Data from the US Department of Agriculture's (USDA) 1995 Continuing Survey of Food Intakes by Individuals (CSFII) suggested that food eaten away from home is generally higher in fat, saturated fat, and lower in dietary fiber. ${ }^{12}$ Higher intake of fat and saturated fat, and lower intake of dietary fiber lead to an increase in total and LDL cholesterol levels. ${ }^{13-16}$ While theoretically plausible, the impact of eating away-from-home on blood cholesterol has not been documented.

The purpose of the present investigation is to examine the associations of eating frequency, and meals eaten away-fromhome with levels of blood total cholesterol in free-living healthy adults. 


\section{METHODS}

\section{Subject Recruitment and Study Design}

The Seasonal Variation in Blood Cholesterol Levels Study (SEASONS) is funded by The National Heart, Lung, and Blood Institute (NHLBI), it was designed to describe and prospectively evaluate the nature and cause of seasonal variation in blood lipid levels. The major factors investigated were dietary fat, physical activity, exposure to light, psychological variables, weather patterns, and body weight.

Most SEASONS participants were recruited from among members of the Fallon Healthcare Systems, a health maintenance organization (HMO) in the central Massachusetts/Worcester area. Additional individuals of Hispanic descent, the largest minority community in Worcester, MA, were recruited from outside of the HMO population to increase the diversity of the SEASONS population. Individuals who were residents of Worcester County, aged 20 to 70 years, and who had telephone service were eligible to participate. In addition, individuals were eligible if they also were: 1 ) not taking cholesterol-lowering medications; 2) not actively on lipid-lowering or weightcontrol diets; 3) free from possible causes of secondary hypercholesterolemia (e.g., hyperthyroidism, pregnancy); 4) not working night shift; and 5) free of chronic illness (e.g., cancer, renal disease, heart failure). Subjects were recruited into the study between December 1994 and February 1997 at a rate of approximately 25 subjects per month by Fallon system telemarketers and by a recruiter assigned specifically to recruit members of ethnic minority groups (who were not Fallon members). Each subject was compensated for his/her participation with a free portable blood pressure monitor and a monetary incentive for each completed clinic visit (maximum possible compensation: \$70).

Approximately 5000 subjects were contacted to determine their interest in study participation. From this sample, 1254 met verbal eligibility criteria and consented to making a baseline appointment. Of these subjects, 427 (34\%) failed to attend their first appointments and $140(11 \%)$ did not meet the formal eligibility requirements for the study. The remaining 641 subjects (51\%) completed the baseline questionnaire and at least one blood draw and were considered to have formally entered the study. The Institutional Review Boards of the Fallon Healthcare System and the University of Massachusetts Medical Center approved all subject recruitment and data collection procedures. Each subject signed an approved informed consent form prior to entering the study.

Study participants were seen in the clinic at the initial baseline interview and then every three months over the next year. Serum lipids and body weight were measured once per quarter and three 24-hour dietary recalls, including assessments of food intake on two weekdays and one weekend day, were completed each quarter. The times each individual went to bed at night and arose in the morning were also collected as part of a 24-hour physical activity recall, administered together with the diet recall. Therefore, a total of fifteen 24-hour diet and physical activity recalls were potentially available for each subject, with serum lipids and body weight each measured five times.

Of the 641 subjects formally entering the SEASONS study, twenty-four hour recall completion rates were high with 267 subjects (41.9\%) having all fifteen 24-hour diet recalls, and 503 subjects $(78.8 \%)$ having more than ten 24 -hour diet recalls. One hundred thirty eight had fewer than ten 24-hour diet recalls and four subjects were working night shift (although individuals who worked night shift were excluded, we double checked eating time for breakfast, lunch, and dinner for study subjects to see whether it was correct). These 4 subjects were excluded from the present analyses. We also excluded subjects with fewer than ten diet recalls to achieve more highly reliable dietary information. These exclusions left 499 men and women with a total of 6,931 twenty-fourhour diet recalls available for analysis. The average number of recalls was $13.4(\mathrm{SD}=1.5)$ per subject and average number of lipid measures was $4.79(\mathrm{SD}=0.59)$ per subject.

\section{Dietary Assessment}

Randomly selected 24-hour dietary recalls, three (two weekdays and one weekend) in each quarter of follow-up, were employed to quantify dietary changes over time. Unannounced 24-hour diet recalls have emerged as a favored dietary assessment method to capture changes in behavior because the respondents only have to recall their previous day of dietary intake. ${ }^{17,18}$ The short period of recall is thought to: minimize errors in recall (omission and/or intrusion), ${ }^{19}$ eliminate error due to long-term averaging imposed by longer-term dietary assessments, ${ }^{19}$ and minimize response-set biases in reporting of dietary intake (e.g., social desirability bias). ${ }^{20}$ The 24-hour dietary recall data were collected using the Nutrition Data System (NDS) data entry and nutrient database software developed and maintained by the Nutrition Coordinating Center at the University of Minnesota, Mineapolis, MN. ${ }^{21}$ Dietary variables considered in these analyses were total energy ( $\mathrm{kcal} / \mathrm{day}), \%$ carbohydrate (expressed as a percentage of total energy intake), \% protein, $\%$ total fat intake, $\%$ saturated fat and fiber $(\mathrm{g} / 1,000 \mathrm{kcal})$. In addition, daily averaged eating episodes and proportion of breakfast, lunch, and dinner eaten away from home for each subject were evaluated.

\section{Blood Lipid Assessment}

Fasting (> 12 hours) venous blood samples $(10 \mathrm{mls})$ were obtained after sitting for 15 minutes. Blood plasma was harvested by low-speed centrifugation at $4^{\circ} \mathrm{C}$, aliquoted into individual tubes, and quickly frozen to $-70^{\circ} \mathrm{C}$. On a regular basis, plasma samples were packed in dry ice and shipped for analysis via overnight service to the Centers for Disease Control standardized laboratory at the University of Massachusetts at Lowell. ${ }^{22}$ Total cholesterol was measured in plasma by enzymatic methods using a Beckman System 700 autoanalyzer. ${ }^{23,24}$

\section{Physical Activity Assessment}

Physical activity was assessed at the same time as the diet recalls. Unannounced telephone-administered 24-hour recall interviews of physical activity were conducted by trained 
registered dietitians on two randomly selected weekdays and one randomly selected weekend day within the 4-week period surrounding each clinic visit. The 24-hour physical activity recall used in our study was adapted from methods developed for a seven-day recall of physical activity. ${ }^{25}$ Specifically, subjects were asked to recall the number of hours they had slept the previous night, and the amount of time spent engaged in three types of activity (household, occupational, leisure-time). In addition, subjects were given a handout to familiarize themselves with the activity intensity classification system (light, moderate, hard, and very hard) to be employed during the interview and then asked to rate the intensity of all activities reported. The interviewers used a standardized interview script and entered the activity data directly into an EpiInfo database. ${ }^{26}$ While the subject was still on the phone, interviewers checked that the total duration of activity reported in the 24-hour period was arithmetically correct and summed to no more than 24 hours.

We used methods described by Ainsworth and colleagues 27 to estimate total daily energy expenditure based on the reported time spent at each activity and activity intensity. A validity study was conducted in estimating short-term physical activity using 24 -hour recalls. ${ }^{28}$ Results showed that three $24 \mathrm{HR}$ of physical activity were observed to have a relative validity that was comparable to published data from other short-term activity assessments that also employed the Baecke Questionnaire and activity monitors as criterion measures.

\section{Clinical Data}

Data on demographic variables were collected by selfadministered questionnaire at baseline ( $1^{\text {st }}$ quarter). Smoking status was ascertained at baseline and in each quarter of follow up by self-administered questionnaire. Anthropometric data including height $(\mathrm{m})$, waist and hip circumferences $(\mathrm{cm})$ were measured at baseline and 12months of follow-up. Body mass was measured at each clinic visit, with the subject removing his/her shoes and wearing minimal layers of clothing. Body mass index (BMI) was computed using the following formula: weight $(\mathrm{kg}) /$ height $(\mathrm{m})^{2}$. Subjects were classified as "overweight" if their BMI was equal to or greater than 25 $\mathrm{kg} / \mathrm{m}^{2}$ and as "obese" if their BMI was equal to or greater than $30 \mathrm{~kg} / \mathrm{m}^{2}{ }^{29}$

\section{Statistical Analysis}

Daily average measure of eating episodes, total energy (kcal/day), percent calories from carbohydrate, protein, total fat intake, and saturated fat, and grams of fiber $(\mathrm{g} / 1,000 \mathrm{kcal})$ were derived from repeated 24-hour diet recall data and evaluated.

Previous studies have suggested that meal frequency may be associated with blood lipids. Though different definitions for meals and snacks have been used in previous studies, all definitions include consideration of the minimal time span between intakes and level of calorie intake. In order to more objectively classify eating frequency, we used the definition proposed by Gibney and colleagues, ${ }^{30}$ which classified an eating episode as an event which provides at least $50 \mathrm{kcal}$ (or $210 \mathrm{KJ}$, in the form of food; it is equivalent to a half cup of Coke, one slice of bread, two cups of coffee with milk and sugar, or a quarter of a cup of cereal with milk) with a minimum time interval between episodes of at least 15 minutes. We then tallied the number of eating episodes for each study subject on each day. The average number of eating episodes from all completed 24HR for each subject was used for this analysis. Proportion of "breakfast", "lunch", and "dinner" eaten away from home were computed for each subject based on multiple 24 hour diet recalls. Breakfast, lunch, and dinner were determined based on self report. Total cholesterol was averaged for each subject from all 5 potential measurements.

The purpose of this analysis was to investigate whether aspects of eating patterns are associated with blood lipids. Although we have multiple measurements per subjects, there is a large within subject variation for dietary measures, ${ }^{31}$ especially eating episodes, and proportion of meal eaten away from home. ${ }^{32}$ Using the average of diet provides more precision, therefore, a cross-sectional analysis was conducted to investigate the association between eating patterns and total cholesterol. Linear regression models were used for the analysis, with total cholesterol fitted as the dependent variable.

The eating pattern parameters evaluated were daily average eating episodes and proportion of meals (breakfast, lunch, and dinner) eaten away from home. Covariates, including participants' demographic characteristics (e.g., age, gender, race/ethnicity and smoking status), total physical activity, and total caloric intake, were evaluated as potential confounders of the eating patterns and blood lipids relationship; variables that were significantly associated with total cholesterol at $\alpha=0.20$ or had been associated with total cholesterol in previous studies were considered candidate variables to be entered into the final models, which include age, gender, race/ethnicity, obesity, cigarette smoking, physical activity, alcohol intake, caloric intake, \% saturated fat and dietary fiber. This approach enabled the examination of the association between eating patterns and blood lipids independent of total energy intake, physical activity, and other covariates.

Additional analyses were conducted to compare meal contents eaten at home and away from home. Nutrient variables, including total energy ( $\mathrm{kcal} /$ day), \% carbohydrate (expressed as a percentage of total energy), \% protein, \% total fat intake, \% saturated fat and fiber (g/1,000kcal), were estimated from a linear mixed model using SAS PROC MIXED ${ }^{33}$ with a random intercept for each subject, and within-subject correlation was prescribed as compound symmetry. Analyses were conducted separately for breakfast, lunch, and dinner.

\section{RESULTS}

Descriptive characteristics of the SEASONS cohort were examined (Table 1). Briefly, at baseline, the average age of both men and women was approximately $48 \mathrm{yrs}$ and their 
average BMI's were 28.6 and $26.6 \mathrm{~kg} / \mathrm{m}^{2}$, respectively. Forty-eight percent of men and $33 \%$ of women were overweight (BMI $25-29.9 \mathrm{~kg} / \mathrm{m}^{2}$ ), and $27 \%$ and $17 \%$ were obese (BMI >=30 kg/m ${ }^{2}$ ), respectively. Average total cholesterol was $219 \mathrm{mg} / \mathrm{dl}(\mathrm{SD}=40)$. The study participants were predominantly white, married, educated, non-smokers, and employed in white-collar occupations (e.g., managerial, scientific, or office work).

Table 2 presents associations between participants' characteristics and total blood cholesterol. Increasing age was significantly associated with higher total cholesterol. BMI was also significantly associated with total cholesterol; overweight or obese subjects had higher total cholesterol than subjects with normal weight. Total cholesterol level did not statistically differ by gender, or by smoking status, physical activity level, and total energy intake.

The associations between average daily number of eating episodes and total cholesterol are presented in Table 3. Mean concentration of total cholesterol was not significantly different among three categories of eating episodes for the unadjusted and adjusted means. When analyses were stratified by gender, total cholesterol was shown to be similar for men among three categories of eating episodes for both the unadjusted and adjusted means. For women, although not statistically significant, mean concentration of total cholesterol decreased with increased eating episodes in a continuous relation. The total cholesterol for subjects with three or less eating episodes per day was $218 \mathrm{mg} / \mathrm{dl}, 211$ $\mathrm{mg} / \mathrm{dl}$ for 4 eating episodes, and $209 \mathrm{mg} / \mathrm{dl}$ for five or more episodes.

On average, subjects ate $18.9 \%$ of breakfast, $53.5 \%$ of lunch and $19.6 \%$ of dinner away from home. Associations between proportion of meals eaten away from home and participants' characteristics are examined and results are presented in Table 4. Briefly, factors associated with eating away from home are gender, race/ethnicity, age, educational levels, and occupation categories; subjects with younger age, male gender, non-white race, higher education and white collar occupations are more likely to eat out.

Table 5 presents nutrient density by meal type and meal place. Breakfasts or dinners eaten away from home were significantly higher in total calories, percentage of calories from total fat ( $\%$ total fat), and $\%$ saturated fat, lower in $\%$ protein, $\%$ carbohydrate and fiber than breakfasts or dinners eaten at home. For example, breakfasts eaten away from home had 105 more kcal, $7 \%$ more fat, $2.8 \%$ more saturated fat and $2.2 \mathrm{~g} / 1000 \mathrm{kcal}$ less fiber; while dinners eaten away from home had 194 more kcal, 3.5\% more fat, and $0.7 \%$ more saturated fat than dinners eaten at home. Lunches eaten away from home were significantly higher in total calories and $\%$ total fat, but lower in $\%$ protein than lunches eaten at home.

Table 6 presents the relationship between the proportion of meals eaten away from home and total cholesterol. Two adjusted means are presented in the table. The first was adjusted for age, gender, race/ethnicity, obesity, cigarette smoking, and physical activity. The second was adjusted for the variables listed for the first mean, plus other dietary variables including alcohol intake, caloric intake, \% saturated fat, and dietary fiber. Results showed that the two adjusted means for each category were very similar, and the decision was made to present the mean that was adjusted for all possible covariates. Increased proportion of breakfast eaten away from home was positively associated with total cholesterol. Subjects in the upper quartile for proportion of breakfast eaten away from home had total cholesterol 11 $\mathrm{mg} / \mathrm{dl}$ higher than subjects in the $1^{\text {st }}$ quartile. Similarly, increased proportion of lunches or dinners eaten away from home was also positively associated with increased total cholesterol. Subjects in the highest quartile for proportion of lunches eaten away from home had total cholesterol $19 \mathrm{mg} / \mathrm{dl}$ higher than subjects in the $1^{\text {st }}$ quartile of the distribution. Subjects in the upper quartile for proportion of dinner eaten away from home had total cholesterol $11 \mathrm{mg} / \mathrm{dl}$ higher than subjects in the $1^{\text {st }}$ quartile. We also stratified the analysis by gender, with the results showing that the differences of total cholesterol among the four categories of proportion were similar between men and women $(\mathrm{P}>0.05$ for interaction term between gender and categories of meal proportion eaten away from home).

Adjusting for covariates including age, gender, race/ethnicity, BMI, cigarette smoking, and physical activity made the association between total cholesterol and eating patterns stronger. To investigate this, we fit a series of models adding each covariate individually to the base model of total cholesterol and eating patterns. The results suggested that race/ethnicity and BMI were the most important covariates that alter these associations.

\section{DISCUSSION}

The results from our study do not support the hypothesis that the number of eating episodes per day is associated with total blood cholesterol. However, we noted that the mean concentration of total cholesterol decreased with increasing number of eating episodes among women, although the adjusted mean among three categories of number of eating episodes per day was not statistically significant. On the other hand, the results of our study suggest that increased frequency of meals (breakfast, lunch, or dinner) eaten away from home was positively associated with mean total blood cholesterol concentration. Furthermore, meals eaten away from home, especially breakfast and dinner, were significantly higher in total calories, percent calories from total fat and saturated fat, but lower in percent calories from protein and carbohydrate, and grams of fiber, than corresponding meals eaten at home.

Results from previous studies suggest that the number of eating episodes per day may be causally associated with blood lipids. Insulin stimulates the activity of 3-hydroxy-3methylglutaryl coenzyme A (HMG-CoA) reductase, an enzyme that plays a pivotal role in regulating the synthesis of cholesterol in the liver. Several lines of evidence have shown that a low number of eating episodes is associated with 
higher 24-hour insulin concentrations ${ }^{1,3,6,7,34}$ when compared to a high number of eating episodes. Eating multiple, small meals suppresses hunger and decreases overall serum insulin concentration, ${ }^{7}$ thereby lowering cholesterol production.

Several small, short-term trials in healthy individuals with normal blood lipids have demonstrated that increased frequency of eating may be associated with improved lipoprotein profiles. ${ }^{1-9}$ Data from a free-living population in Europe ${ }^{11}$ suggest that concentration of total cholesterol is negatively and consistently associated with frequency of eating. Our results suggest a similar trend. However, there are some differences between the European study and ours. First, we had a small sample size compared with the
European study, so we may not have adequate power to detect the association between number of eating episodes and total cholesterol. In our study we observed a $4 \%$ reduction in total cholesterol among women reporting five or more episodes, compared with those reporting less than three eating episodes per day, although this did not reach statistical significance. This is similar to that reported in the European study: a 5\% decrease in subjects who ate six or more times a day compared to those who ate once or twice a day. Second, eating episodes were measured quite differently: eating frequency was assessed by a simple question in the European study, while our measures were obtained from averaging up to fifteen 24-hour recalls performed during a one-year period, and therefore less subject to within person variation.

Table 1. Baseline Demographic Characteristics of Subjects (N=499), Seasonal Variation of Blood Cholesterol Study, Worcester, Massachusetts, 1994-1998.

\begin{tabular}{|c|c|}
\hline & $\%$ \\
\hline \multicolumn{2}{|l|}{ Gender } \\
\hline Male & 50.3 \\
\hline \multicolumn{2}{|l|}{ Race } \\
\hline White & 87.7 \\
\hline Hispanic & 7.2 \\
\hline \multicolumn{2}{|l|}{ Education } \\
\hline High school or less & 30.8 \\
\hline Post-high school & 29.4 \\
\hline Bachelor degree or more & 39.8 \\
\hline \multicolumn{2}{|l|}{ Smoking Status } \\
\hline Yes & 15.2 \\
\hline \multicolumn{2}{|l|}{ Occupational Category } \\
\hline Unemployed/retired & 21.8 \\
\hline Blue collar & 13.5 \\
\hline Service work & 27.3 \\
\hline White collar & 37.4 \\
\hline \multicolumn{2}{|l|}{ Marital Status } \\
\hline Married & 78.1 \\
\hline Not married & 21.9 \\
\hline \multicolumn{2}{|l|}{ Age (years) } \\
\hline $20-39$ & 25.3 \\
\hline $40-59$ & 50.9 \\
\hline $60-70$ & 23.8 \\
\hline \multicolumn{2}{|c|}{ Body Mass Index Classification } \\
\hline Normal Weight (17.1-24.9) & 37.5 \\
\hline Overweight (25.0-29.9) & 39.3 \\
\hline Obese $(>=30.0)$ & 23.2 \\
\hline
\end{tabular}


Table 2. Mean Values of Blood Lipids for Participants' Characteristics Adjusted for Age and Gender, Seasonal Variation of Blood Cholesterol Study, Worcester, Massachusetts (N=499), 1994-1998.

\begin{tabular}{|c|c|c|}
\hline & n $(\%)$ & $\begin{array}{c}\text { Total Cholesterol (mg/dl) } \\
\text { Mean (SE) }\end{array}$ \\
\hline \multicolumn{3}{|l|}{ Age 1} \\
\hline $20-30$ & $28(5.61)$ & $188(7.21)$ \\
\hline $30-40$ & $98(19.64)$ & $208(3.85)$ \\
\hline $40-50$ & $140(28.06)$ & $212(3.22)$ \\
\hline $50-60$ & $114(22.85)$ & $231(3.57)$ \\
\hline $60-70$ & $119(23.85)$ & $231(3.50)$ \\
\hline p-value* & & $<0.001$ \\
\hline \multicolumn{3}{|l|}{ Gender $¥$} \\
\hline Male & $251(50.30)$ & $216(2.68)$ \\
\hline Female & $248(49.70)$ & $212(2.62)$ \\
\hline $\mathrm{p}$-value & & 0.27 \\
\hline \multicolumn{3}{|l|}{ Race } \\
\hline White & $426(87.65)$ & $217(2.31)$ \\
\hline Others & $60(12.35)$ & $205(4.99)$ \\
\hline$p$-value & & 0.046 \\
\hline \multicolumn{3}{|l|}{ Smoking Status } \\
\hline Never & $401(86.98)$ & $214(2.25)$ \\
\hline Ever & $60(13.02)$ & $211(5.16)$ \\
\hline p-value & & 0.55 \\
\hline \multicolumn{3}{|l|}{$\begin{array}{l}\text { Physical Activity } \\
\text { (MET-hr/day) }\end{array}$} \\
\hline Quartile 1 (5.6 Met-hr/day)§ & & $216(3.60)$ \\
\hline $2(8.4)$ & & $212(3.66)$ \\
\hline $3(11.2)$ & & $212(3.63)$ \\
\hline $4(17.7)$ & & $215(3.65)$ \\
\hline p-value & & 0.8265 \\
\hline \multicolumn{3}{|l|}{ Total Energy Intake (Kcal/d) } \\
\hline Quartile 1 & & $221(3.62)$ \\
\hline 2 & & $213(3.55)$ \\
\hline 3 & & $212(3.60)$ \\
\hline 4 & & $209(3.58)$ \\
\hline p-value & & 0.0960 \\
\hline \multicolumn{3}{|l|}{ Body Mass Index Classification } \\
\hline Normal Weight (17.1-24.9) & $180(30.07)$ & $204(2.97)$ \\
\hline Overweight (25.0-29.9) & $203(40.68)$ & $218(2.94)$ \\
\hline Obese $(>=30.0)$ & $116(23.25)$ & $223(3.65)$ \\
\hline$p$-value & & $<0.001$ \\
\hline
\end{tabular}

*: P-value for test of adjusted mean difference across categories.

$\dagger$ : Sex-specific quartile cutpoints used. Median quartile values for men=1703, 2055, 2383, and 2836. Median quartile values for women $=1259,1486,1724$, and 2078 .

$\S:$ Median values for Met-hr/day in each quartile.

II: Adjusted for sex only.

$¥:$ Adjusted for age only. 
Table 3. Mean Values of Total Cholesterol (mg/dl) by Reported Daily Eating Episodes, Seasonal Variation of Blood Cholesterol Study, Worcester, Massachusetts, 1994-1998.

\begin{tabular}{|c|c|c|c|c|c|c|c|c|c|}
\hline & \multicolumn{3}{|c|}{ Total } & \multicolumn{3}{|c|}{ Men } & \multicolumn{3}{|c|}{ Women } \\
\hline $\begin{array}{l}\text { Average Daily } \\
\text { Number of Eating } \\
\text { Episodes }\end{array}$ & $\bar{n}$ & Unadjusted & $\begin{array}{c}\text { Adjusted } \\
\dagger\end{array}$ & $\mathbf{n}$ & $\begin{array}{c}\text { Unadjuste } \\
\text { d }\end{array}$ & Adjusted $\$$ & $\mathbf{n}$ & Unadjusted & Adjusted $\uparrow$ \\
\hline 3 or less & 141 & $221(3.38)$ & $216(4.78)$ & 81 & $224(4.22)$ & $219(7.16)$ & 60 & $217(5.45)$ & $218(6.45)$ \\
\hline 4 & 264 & $218(2.47)$ & $213(4.33)$ & 128 & $220(3.35)$ & $219(6.67)$ & 136 & $215(3.62)$ & $211(5.71)$ \\
\hline 5 or more & 94 & $217(4.13)$ & $213(5.18)$ & 42 & $217(5.85)$ & $220(8.87)$ & 52 & $216(5.85)$ & $209(6.80)$ \\
\hline p-value $\S$ & & 0.66 & 0.81 & & 0.60 & 0.99 & & 0.99 & 0.50 \\
\hline
\end{tabular}

Table 4. Proportion of Meals Eaten Away from Home by Participants' Characteristics, Seasonal Variation of Blood Cholesterol Study, Worcester, Massachusetts (N=499), 1994-1998.

\begin{tabular}{|c|c|c|c|c|}
\hline & n (\%) & $\begin{array}{c}\text { Breakfast } \\
\text { Mean (SE) }\end{array}$ & $\begin{array}{c}\text { Lunch } \\
\text { Mean (SE) }\end{array}$ & $\begin{array}{c}\text { Dinner } \\
\text { Mean (SE) }\end{array}$ \\
\hline \multicolumn{5}{|l|}{ Age } \\
\hline $20-30$ & $28(5.61)$ & $25.22(3.56)$ & $58.41(4.54)$ & $22.42(3.15)$ \\
\hline $30-40$ & $98(19.64)$ & $26.45(1.90)$ & $62.84(2.42)$ & $23.23(1.68)$ \\
\hline $40-50$ & $140(28.06)$ & $18.93(1.59)$ & $62.79(2.03)$ & $20.21(1.41)$ \\
\hline $50-60$ & $114(22.85)$ & $18.86(1.77)$ & $54.36(2.25)$ & $19.46(1.56)$ \\
\hline $60-70$ & $119(23.85)$ & $11.11(1.73)$ & $33.11(2.20)$ & $15.30(1.53)$ \\
\hline p-value* & & $<0.001$ & $<0.001$ & 0.0092 \\
\hline \multicolumn{5}{|l|}{ Gender } \\
\hline Male & $251(50.30)$ & $21.72(1.33)$ & $56.17(1.73)$ & $21.11(1.18)$ \\
\hline Female & $248(49.70)$ & $16.00(1.10)$ & $50.90(1.64)$ & $18.09(0.92)$ \\
\hline $\mathrm{p}$-value & & 0.001 & 0.03 & 0.04 \\
\hline \multicolumn{5}{|l|}{ Race } \\
\hline White & $426(87.65)$ & $17.80(0.91)$ & $52.57(1.31)$ & $19.76(0.83)$ \\
\hline Others & $60(12.35)$ & $27.81(2.86)$ & $60.98(3.05)$ & $19.21(2.06)$ \\
\hline $\mathrm{p}$-value & & 0.0002 & 0.02 & 0.81 \\
\hline \multicolumn{5}{|l|}{ Smoking Status } \\
\hline Never & $401(86.98)$ & $18.43(0.96)$ & $52.81(1.31)$ & $20.19(0.85)$ \\
\hline Ever & $60(13.02)$ & $22.12(2.80)$ & $58.94(3.23)$ & $18.28(2.38)$ \\
\hline p-value & & 0.17 & 0.09 & 0.42 \\
\hline \multicolumn{5}{|l|}{ Education } \\
\hline$\leq$ High school & $152(30.83)$ & $19.61(1.58)$ & $48.93(2.17)$ & $15.98(1.36)$ \\
\hline Some college & $145(29.41)$ & $20.63(1.62)$ & $54.05(2.22)$ & $19.39(1.39)$ \\
\hline$\geq$ Bachelor degree & $196(39.76)$ & $17.29(1.39)$ & $56.80(1.91)$ & $22.63(1.19)$ \\
\hline p-value & & 0.27 & 0.02 & 0.001 \\
\hline \multicolumn{5}{|l|}{ Occupational Category } \\
\hline White collar & $185(37.37)$ & $20.22(1.40)$ & $61.28(1.81)$ & $22.84(1.23)$ \\
\hline Service work & $135(27.27)$ & $21.08(1.64)$ & $58.33(2.11)$ & $17.71(1.44)$ \\
\hline Blue collar & $67(13.54)$ & $23.76(2.33)$ & $55.15(3.00)$ & $18.26(2.05)$ \\
\hline Unemployed/retired & $108(21.82)$ & $11.00(1.84)$ & $33.18(2.30)$ & $17.52(1.61)$ \\
\hline $\mathrm{p}$-value & & $<0.0001$ & $<0.0001$ & 0.014 \\
\hline
\end{tabular}

*: P-value for test of mean difference across categories using t-test or analysis of variance. 
Table 5. Nutrient Density by Meal Type and Meal Place, Seasonal Variation of Blood Cholesterol Study, Worcester, Massachusetts (N=499), 1994-1998.

\begin{tabular}{|l|c|l|l|l|l|c|c|}
\hline & $\begin{array}{l}\text { Number } \\
\text { of Meals }\end{array}$ & $\begin{array}{l}\text { Energy } \\
(\mathbf{k c a l})\end{array}$ & $\begin{array}{l}\text { Total Fat } \\
(\boldsymbol{\%})\end{array}$ & $\begin{array}{l}\text { Saturated } \\
\text { Fat }(\boldsymbol{\%})\end{array}$ & Protein (\%) & $\begin{array}{l}\text { Carbohydrate } \\
(\boldsymbol{\%})\end{array}$ & $\begin{array}{l}\text { Fiber } \\
(\mathbf{g} / \mathbf{1 , 0 0 0} \text { kcal) }\end{array}$ \\
\hline & $\mathbf{n}$ & Mean (SE) & Mean (SE) & Mean (SE) & Mean (SE) & Mean (SE) & Mean (SE) \\
\hline Breakfast & & & & & & & \\
\hline At Home & 5889 & $334 \pm 7.2$ & $21.9 \pm 0.5$ & $9.2 \pm 0.3$ & $12.5 \pm 0.1$ & $68.2 \pm 0.5$ & $12.1 \pm 0.3$ \\
\hline $\begin{array}{l}\text { Away from } \\
\text { home }\end{array}$ & 1351 & $439 \pm 9.4$ & $28.9 \pm 0.6$ & $12.0 \pm 0.3$ & $11.8 \pm 0.2$ & $60.8 \pm 0.6$ & $9.9 \pm 0.4$ \\
\hline p-value & & $<0.001$ & $<0.001$ & $<0.001$ & $<0.001$ & $<0.001$ & $<0.001$ \\
\hline & & & & & & & \\
\hline Lunch & & & & & & & \\
\hline At Home & 2835 & $542 \pm 10.7$ & $31.4 \pm 0.4$ & $10.7 \pm 0.2$ & $18.3 \pm 0.2$ & $50.3 \pm 0.5$ & $9.4 \pm 0.2$ \\
\hline $\begin{array}{l}\text { Away from } \\
\text { home }\end{array}$ & 3192 & $606 \pm 10.4$ & $32.6 \pm 0.4$ & $10.7 \pm 0.2$ & $17.5 \pm 0.2$ & $50.0 \pm 0.5$ & $9.3 \pm 0.2$ \\
\hline p-value & & $<0.001$ & 0.001 & 0.8147 & $<0.001$ & 0.5532 & 0.6795 \\
\hline & & & & & & \\
\hline Dinner & & & & & & & \\
\hline At Home & 5272 & $758 \pm 11.7$ & $31.2 \pm 0.3$ & $10.8 \pm 0.1$ & $20.4 \pm 0.2$ & $46.4 \pm 0.4$ & $9.3 \pm 0.1$ \\
\hline $\begin{array}{l}\text { Away from } \\
\text { home }\end{array}$ & 1265 & $952 \pm 15.6$ & $34.7 \pm 0.4$ & $11.5 \pm 0.2$ & $18.8 \pm 0.3$ & $41.7 \pm 0.5$ & $7.6 \pm 0.2$ \\
\hline p-value & & $<0.001$ & $<0.001$ & $<0.001$ & $<0.001$ & $<0.001$ & $<0.001$ \\
\hline
\end{tabular}

Table 6. Mean Values of Total Cholesterol by Categories of Proportion of Meals Eaten Away from Home, Seasonal Variation of Blood Cholesterol Study, Worcester, Massachusetts, 1994-1998.

\begin{tabular}{|c|c|c|c|}
\hline & Unadjusted & Adjusted $\mathscr{I}$ & Adjusted§ \\
\hline \multicolumn{4}{|l|}{ Breakfast } \\
\hline Quartile 1 (median=0\% of breakfasts away from home) & $216(3.69)$ & $209(5.16)$ & $206(5.15)$ \\
\hline $2(6.7 \%)$ & $217(3.60)$ & $213(5.17)$ & $212(5.13)$ \\
\hline $3(18.2 \%)$ & $223(3.44)$ & $222(4.84)$ & $219(4.86)$ \\
\hline $4(46.2 \%)$ & $217(3.64)$ & $219(4.65)$ & $217(4.74)$ \\
\hline p-value & 0.8155 & 0.0493 & 0.0488 \\
\hline \multicolumn{4}{|l|}{ Lunch } \\
\hline Quartile 1 (median= $15.1 \%$ of lunches away from home) & $218(3.63)$ & $204(5.08)$ & $203(5.06)$ \\
\hline $2(45.5 \%)$ & $219(3.63)$ & $216(4.85)$ & $213(4.94)$ \\
\hline $3(66.7 \%)$ & $217(3.53)$ & $220(4.71)$ & $218(4.72)$ \\
\hline $4(83.3 \%)$ & $227(3.58)$ & $226(4.97)$ & $222(5.04)$ \\
\hline p-value $t$ & 0.6789 & 0.0001 & 0.0004 \\
\hline \multicolumn{4}{|l|}{ Dinner } \\
\hline Quartile 1 (median $=0 \%$ of dinners away from home) & $213(3.93)$ & $209(5.17)$ & $207(5.16)$ \\
\hline $2(9.1 \%)$ & $220(3.42)$ & $218(4.55)$ & $216(4.57)$ \\
\hline $3(20.0 \%)$ & $220(3.57)$ & $219(5.11)$ & $216(5.15)$ \\
\hline $4(38.5 \%)$ & $220(3.49)$ & $221(4.90)$ & $218(4.99)$ \\
\hline p-value + : & 0.1919 & 0.0264 & 0.0389 \\
\hline
\end{tabular}

†: P-value was from test of difference among means or adjusted means from whom the proportion of meals eaten away from home from 4 quartiles of the distribution.

II: Adjusted for age, gender, race/ethnicity, obesity, cigarette smoking, and physical activity.

$\S$ : Adjusted for age, gender, race/ethnicity, obesity, cigarette smoking, physical activity, alcohol intake, caloric intake, \% saturated fat and dietary fiber. 
Results from our study indicate that meals eaten away from home were higher in total calories, percent calories from total fat and saturated fat, and lower in percent calories from protein and carbohydrates, and in grams of fiber than corresponding meals eaten at home. These results are similar to results from the US Department of Agriculture's (USDA) 1995 Continuing Survey of Food Intakes by Individuals (CSFII). ${ }^{12}$

Results from our study suggest that subjects who eat a larger proportion of meals away from home tend to have higher total cholesterol levels. This association was not significantly altered after controlling for covariates including total energy intake, and fat, saturated fat, and dietary fiber intake. This agrees with results reported by Jacobs, ${ }^{35}$ in which he found no association between dietary fat and serum lipids in a cross-sectional analysis.

There are several theories as to explain the association between eating away from home and total cholesterol. First, dietary glycemic index (GI) and glycemic load (GL) could be different in foods eaten away from home, as several studies have shown an association of GI and GL with blood lipids. 36,37 Secondly, the "Western" diet, which is characterized by a higher intake of red and processed meat, high-fat dairy products, sugar-containing beverages, sweets and desserts, may be associated with a higher fasting insulin concentration than the "Prudent" diet (higher intake of fruit, vegetables, whole grains, and poultry). ${ }^{38}$ Thus the "Western" diet affects blood lipids. ${ }^{38}$ Finally, studies have shown that hydrogenated fat consumption affects blood cholesterol. ${ }^{39,40}$

Hydrogenated oils not only raise total cholesterol and LDL cholesterol levels but also are known to lower HDL cholesterol levels. As discussed by Willett, ${ }^{41}$ most restaurants and fast food establishments prepare foods using hydrogenated oils (because when liquid oils are hydrogenated, the oils become more solid, more stable, and less greasy-tasting); most processed foods are also made with hydrogenated fat. The spread of fast food restaurants and processed foods all over the world has changed modern nutrition fundamentally. The influence begins early in childhood. Advertising concentrates on the selling of image over substance. However, fast foods and processed foods contain high levels of fat, especially trans fatty acids. ${ }^{41}$ Higher consumption of trans fatty acids has been associated with a higher incidence of morbidity and mortality from coronary heart disease. $^{42-44}$

In our study, the magnitude of the change in total blood cholesterol was a difference of $9 \mathrm{mg} / \mathrm{dl}$ (4\%) between subjects reporting five or more episodes compared with subjects reporting fewer than 3 eating episodes per day. Looking at the quartile distribution, we found an $11 \mathrm{mg} / \mathrm{dl}$ difference in total blood cholesterol between subjects in the $1^{\text {st }}$ quartile of the distribution of number of breakfasts or dinners eaten away from home and subjects in the 4th quartile of that distribution. This difference in cholesterol concentration is clinically relevant, since it is comparable to that achieved in clinical trials involving changes in dietary intake of fat and saturated fat, ${ }^{45}$ as well as in controlled trials of eating frequency. ${ }^{7} \mathrm{~A} 10 \mathrm{mg} / \mathrm{dl}$ reduction in total cholesterol concentration has been associated with reductions in coronary heart disease ranging from $10 \%$ to $21 \%$ in observational studies and trials. $^{46,47}$ If applied to the entire population, such a reduction may have a substantial impact, particularly in older people, who have higher absolute rates of heart disease. ${ }^{48}$

Since the study has a cross-sectional design, causality cannot be determined. Therefore, further investigation of this association in other populations using cohort studies or clinical trials is warranted. The relationship between total cholesterol and eating out might be explained by confounding factors. However, this association persisted after adjustment variables including age, gender, dietary intake, BMI, smoking status, physical activity and dietary intake, suggesting that the frequency of meals eaten away from home influences blood lipids through other mechanisms (e.g. hydrogenated fat), but we can not explain such mechanism in this study. Finally, there is a potential limitation in generalizing our study results. Participants in this study were highly motivated, ages between 20 and 70 years, predominantly well-educated, employed full time, and white. In conclusion, the results of this study suggest that total blood cholesterol levels might be correlated with number of eating episodes per day, but the association did not achieve statistical significance. On the other hand, total blood cholesterol levels appear to be positively related with the frequency of meals eaten away from home. Further research is needed to better understand the role of eating away from home on blood lipids.

\section{DISCOLSURE}

The project described was supported by grant No. R01-HL52745 to Dr. Ira S. Ockene from the National Heart, Lung and Blood Institute (NHLBI). Its contents are solely the responsibility of the authors and do not necessarily represent the official views of the NHLBI.

\section{ACKNOWLEDGEMENTS}

The authors thank Laura Robidoux and Priscilla Cirillo for their assistance with study recruitment and data collection; Kelly Scribner for coordination of the 24-hour recalls; and the SEASONS dieticians who conducted the recalls. Dietitians included Susan Nelson, Christine Singelton, Pat Jeans, Karen Lafayette, Deborah Lamb, Stephanie Olson, and Eileen Capstraw. The authors also thank Drs. Charles Matthews and Patty Freedson for their contribution on physical activity measurements, Thomas Hurley for his organizational and data management expertise and Drs. Philip C Nasca and David Chiriboga for their insightful critiques of early drafts of the manuscript.

\section{CONFLICT OF INTEREST}

None.

\section{REFERENCES}

1. Gwinup G, Bryon RC, Roush WH, Kruger FA, Hamwi GJ. Effect of nibbling versus gorging on serum lipids in man. Am J Clin Nutr. 1963;13:209-213.

2. Cohn C. Feeding patterns and some aspects of cholesterol metabolism. Federation Proceedings. 1964;23:76-81.

3. Nunes WT, Canham JE. The effect of varied periodicity of eating on plasma lipids in free living healthy males on normal self selected diets. Am J Clin Nutr. 1963;12:334.

4. Bortz WM, Wroldsen A, Issekutz B, Rodahl K. Weight loss and frequency of feeding. N Engl J Med. 1966;274(7):376-379. 
5. Irwin MI, Feeley RM. Frequency and size of meals and serum lipids, nitrogen and mineral retention, fat, digestibility, and urine thiamine and riboflavin in young women. Am J Clin Nutr.1967;20(8):816-824.

6. Young CM, Hutter LF, Scanlan SS, Rand CE, Lutwak L, Simko V. Metabolic effects of meal frequency on normal young men. J Am Diet Assoc. 1972;61(4):391-398.

7. Jenkins DJA, Wolever TMS, Vuksan V, et al. Nibbling versus gorging: metabolic advantages of increased meal frequency. N Engl J Med. 1989;321(14):929-934.

8. McGrath S, Gibney MJ. The effects of altered frequency of eating on plasma lipids in free living healthy males on normal self selected diets. Eur J Clin Nutr 1994;48(6):402-407.

9. Arnold LM, Ball M, Mann J. Effect of isoenergetic intake of three or nine meals on plasma lipoproteins and glucose metabolism. Am J Clin Nutr. 1993;57(3):446-451.

10. Jones PJH, Leitch CA, Pederson RA. Meal-frequency effects on plasma hormone concentrations and cholesterol synthesis in humans. Am J Clin Nutr. 1993;57(6):868-874.

11. Titan S, Bingham S, Welch A, et al. Frequency of eating and concentrations of serum cholesterol in the Norfolk population of the European prospective investigation into cancer (EPIC-Norfolk): cross sectional study. BMJ. 2001;323(7324):1286-1288.

12. Lin BH, Guthrie J, Frazao E. Away-from-home foods increasingly important to quality of American diet. Washington, DC: US Dept of Agriculture, Economic Research Service; 1999. No. 749.

13. Hegsted DM, McGandy RB, Myers ML, Stare FJ. Quantitative effects of dietary fat on serum cholesterol in man. Am $\mathbf{J}$ Clin Nutr. 1965;17(5):281-295.

14. Shekelle RB, Shryock AM, Paul O, et al. Diet, serum cholesterol, and death from coronary heart disease. N Engl J Med. 1981;304(2):65-70.

15. Keys A. Seven countries: A multivariate analysis of death and coronary heart disease. Cambridge, MA: Harvard Univ Press; 1980.

16. Kushi LH, Lew RA, Stare FJ, et al, Kevaney J. Diet and 20-year mortality from coronary heart disease-The Ireland-Boston Diet-Heart Study. N Engl J Med. 1985;312(13):811-818.

17. Buzzard IM, Faucett CL, Jeffery RW, et al. Monitoring dietary change in a low-fat diet intervention study: Advantages of using 24-hour dietary recalls vs food records. J Am Diet Assoc. 1996;96(6):574-579.

18. Beaton G. Approaches to analysis of dietary data: relationship between planned analyses and choices of methodology. Am J Clin Nutr. 1994;59(1 Suppl):S253-S261.

19. Smith AF. Cognitive psychological issues of relevance to the validity of dietary reports. Eur J Clin Nutr. 1993;47(Suppl 2):S6-S18.

20. Hebert JR, Clemow L, Pbert L, Ockene IS, Ockene JK. Social desirability and approval biases in dietary self-report may profoundly compromise the validity of diet-disease studies. Int $\mathrm{J}$ Epidemiol. 1995;24(2):389-398.

21. Buzzard IM, Price KS, Warren RA. Considerations for selecting nutrient-calculation software: evaluation of the nutrient database. Am J Clin Nutr. 1991;54(1):7-9.

22. Karge W, Weiner E, Rogers E, Nicolosi R. Evaluation of cholesterol measurement using the Beckman System 700 Analyzer in the CDCNHLBI Standardization Program. Clin Chem. 1989;35(8):1790-1798.

23. Alain C, Poon L, Chan W. Enzymatic determination of total serum cholesterol. Clin Chem. 1974;20(4):470-475.

24. Bucolo G, David H. Quantitative determinations of serum triglycerides by use of enzymes. Clin Chem. 1973;19(5):476-482.

25. Sallis J, Haskell W, Wood P, et al. Physical activity assessment methodology in the Five-City Project. Am J Epidemiol. 1985;121(1):91-106.

26. Dean A, Dean J, Coulombier D, et al. Epi Info, Version 6.0: A Word Processing, Database, and Statistics Program for Epidemiology on Microcomputers. Atlanta, GA: Centers for Disease Control and Prevention; 1994.
27. Ainsworth B, Haskell W, Leon A, et al. Compendium of physical activities: classification of energy costs of human physical activities. Med Sci Sports Exerc. 1993;25(1):71-80.

28. Matthews CE, Freedson P, Hebert J, Stanek E, Ockene I, Merriam P. Comparison of physical activity assessment methods in the Seasonal Variation of Blood Cholesterol Levels Study. Med Sci Sports Exerc. 2000;32(5):976-984.

29. NHLBI. Clinical Guidelines on the Identification, Evaluation, and Treatment of Overweight and Obesity In Adults: the Evidence Report. Bethesda, MD: National Institutes of Health, National Heart, Lung, and Blood Institute; June 1998.

30. Gibney M, Wolever T. Periodicity of eating and human health: present perspective and future directions. Br J Nutr. 1997;77(Suppl. 1):S3-S5.

31. Beaton GH, Milner J, McGuire V, Feather TE, Little JA. Source of variance in 24-hour dietary recall data: Implications for nutrition study design and interpretation. carbohydrate sources, vitamins, and minerals. Am J Clin Nutr. 1983;37(6):986-995.

32. Ma Y, Bertone-Johnson E, Stanek EI, et al. Eating Patterns in a Freeliving Healthy U.S. Adult Population. Ecology of Food and Nutrition. 2005;44(1):37-56.

33. Littell R, Milliken G, Stroup W, Wolfinger R. SAS System for Mixed Models. Cary, NC: SAS Institute Inc; 1996.

34. Wadhwa PS, Young EA, Schmidt K, Elson CE, Pringle DJ. Metabolic consequences of feeding frequency in man. Am $\mathrm{J}$ Clin Nutr. 1973;26(8):823-830.

35. Jacobs DJ, Anderson J, Blackburn H. Diet and serum cholesterol: Do zero correlations negate the relationship? Am $J$ Epidemiol. 1979;110(1):77-87.

36. Liu S, Willett WC, Stampfer MJ, et al. A prospective study of dietary glycemic load, carbohydrate intake, and risk of coronary heart disease in US women. Am J Clin Nutr. Jun 2000;71(6):1455-1461.

37. Jenkins D, Wolever T, Kalmusky J. Low-glycemic index diet in hyperlipidemia: use of traditional starch foods. Am J Clin Nutr. 1987;46(1):66-71.

38. Fung T, Rimm E, Spiegelman D, et al. Association between dietary patterns and plasma biomarkers of obesity and cardiovascular disease risk. Am J Clin Nutr. 2001;73(1):61-67.

39. Matthan N, Cianflone K, Lichtenstein A, Ausman L, Jauhiainen M, Jones P. Hydrogenated fat consumption affects acylation-stimulating protein levels and cholesterol esterification rates in moderately hypercholesterolemic women. J Lipid Res. 2001;42(11):1841-1848.

40. Katan MB, Mensink R, Van Tol A, Zock PL. Dietary trans fatty acids and their impact on plasma lipoproteins. Can J Cardiol. 1995;11(Suppl G):36G-38G.

41. Willett W. Eat Drink and be Healthy: The Harvard Medical School Guide to Healthy Eating. New York: Simon \& Schuster Source; 2001.

42. Chandrasekharan N. Changing concepts in lipid nutrition in health and disease (quiz 428). Med J Malaysia. 1999;54(3):408-427.

43. Kromhout D, Menotti A, Bloemberg B, et al. Dietary saturated and trans fatty acids and cholesterol and 25-year mortality from coronary heart disease: the Seven Countries Study. Prev Med. 1995;24(3):308315 .

44. Lichtenstein AH. Dietary trans fatty acid. J Cardiopulm Rehabil. 2000;20(3):143-146.

45. Ockene IS, Hebert JR, Ockene JK, et al. Effect of physician delivered nutrition counseling training and an office support system on saturated fat intake, weight, and serum lipid measurements in a hyperlipidemic population: The Worcester Area Trial for Counseling in Hyperlipidemia (WATCH). Arch Intern Med. 1999;159(7):725-731.

46. Wald N, Law M. Serum cholesterol and ischaemic heart disease. Atherosclerosis. 1995;118(Suppl):S1-S5.

47. Chen Z, Peto R, Collins R, MacMahon S, Lu J, Li W. Serum cholesterol concentration and coronary heart disease in population with low cholesterol concentrations. BMJ. 1991;303(6797):276-282.

48. Ockene IS, Ockene JK, (Eds). Prevention of Coronary Heart Disease Boston, MA: Little Brown and Company; 1992. 